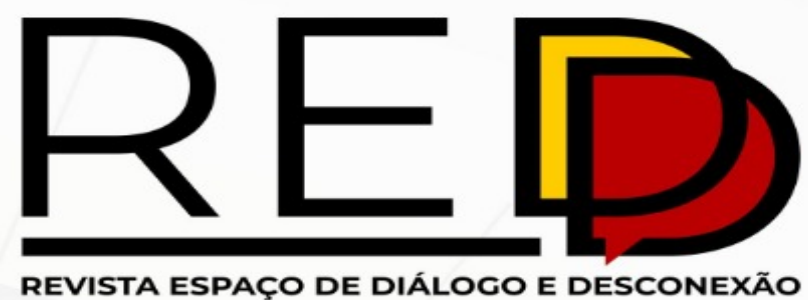

Link: https://periodicos.fclar.unesp.br/redd/index

\title{
ESTUDO DE VIABILIDADE, SUSTENTABILIDADE E EFICÁCIA DA ASSISTÊNCIA ESTUDANTIL EM UNIVERSI- DADES PÚBLICAS ATRAVÉS DE MODELAGEM ORGANIZACIONAL
}

\author{
Renato Aparecido Terezan de Moura ${ }^{1}$. \\ ${ }^{1}$ ID ORCID: https://orcid.org/0000-0001-7427-9882 \\ Autor para correspondência e-mail: renato.terezan@gmail.com
}

\section{Palavras-chave}

Assistência estudantil

Sustentabilidade

Eficácia

Modelagem organizacional

Administração pública.

EKD (Enterprise

Knowledge Development)

\section{Keywords}

Student assistance

Sustainability

Effectiveness

Organizational modeling

Public administration

EKD (Enterprise Knowledge

Development)

\section{Palabras clave}

Asistencia estudiantil

Sostenibilidad

Eficacia

Modelado organizativo

Administración pública

EKD (Enterprise Knowledge

Development)

\section{RESUMO}

A assistência estudantil em universidades públicas tem, por finalidade básica, viabilizar oportunidades igualitárias entre estudantes, evitando, preventivamente, a reprovação e a evasão, visando otimizar o desempenho acadêmico. As políticas públicas de inclusão social, através do acesso ao ensino superior, também se estendem aos meios de garantir assistência em aspectos orgânicos, cognitivos, afetivos e motivacionais do grupo social no qual o aluno está inserido. As universidades públicas, em sua maioria, oferecem amparos assistencialistas aos alunos de comprovada carência socioeconômica, mas que geralmente não abrangem serviços de apoio, orientação e cuidados psicossociais e de saúde à totalidade dos estudantes, que mesmo em menor risco de vulnerabilidade financeira, também podem demandar suporte ao seu desenvolvimento intelectual e social. O presente artigo propõe analisar modelos de assistência social implantados e operacionalizados em universidades públicas paulistas e propor, através da modelagem organizacional baseada na metodologia EKD (Enterprise Knowledge Development), modelos de objetivos, regras, processos e atores que visam mapear requisitos técnicos e componentes operacionais estratégicos que garantam a aplicação eficaz dos recursos financeiros, viabilizando políticas sustentáveis referenciadas pelos princípios constitucionais de legalidade, eficiência e interesse público.

\section{Abstract}

STUDY OF VIABILITY, SUSTAINABILITY AND EFFECTIVENESS OF STUDENT ASSISTANCE IN PUBLIC UNIVERSITIES THROUgh ORganizational Modeling

Student assistance in public universities has, for its basic purpose, to facilitate equal opportunities among students, avoiding, in a preventive way, reprobation and avoidance, in order to optimize academic performance. The public policies of social inclusion, through access to higher education, also extend to the means of guaranteeing assistance in organic, cognitive, affective and motivational aspects of the social group in which the student is inserted. Public universities, for the most part, offer welfare assistance to students with proven socioeconomic needs, but generally do not cover support services, counseling and psychosocial and health care for all students, who, even at a lower risk of financial vulnerability, can also support their intellectual and social development. The present article proposes to analyze models of social assistance implanted and operationalized in public universities in the State of São Paulo and propose, through organizational modeling based on the EKD (Enterprise Knowledge Development) methodology, models of objectives, rules, processes and actors that aim to map technical requirements and operational components strategies that ensure the effective application of financial resources, enabling sustainable policies referenced by the constitutional principles of legality, efficiency and public interest.

\section{RESUMEN}

ESTUdIO DE VIABILIDAD, SOSTENIBILIDAD Y EFICACIA DE LA ASISTENCIA ESTUDIANTE EN UNIVERSIDADES PÚBLICAS A TRAVÉS DE MODELADO ORGANIZACIONAL

La asistencia estudiantil en universidades públicas tiene, por finalidad básica, viabilizar oportunidades igualitarias entre estudiantes, evitando, preventivamente, la reprobación y la evasión, buscando optimizar el desempeño académico. Las políticas públicas de inclusión social, a través del acceso a la enseñanza superior, también se extienden a los medios de garantizar asistencia en aspectos orgánicos, cognitivos, afectivos y motivacionales del grupo social en el cual el alumno está inserto. Las universidades públicas, en su mayoría, ofrecen amparos asistencialistas a los alumnos de comprobada carencia socioeconómica, pero que generalmente no abarcan servicios de apoyo, orientación y cuidados psicosociales y de salud a la totalidad de los estudiantes, que incluso en menor riesgo de vulnerabilidad financiera, también pueden demandar apoyo a su desarrollo intelectual y social. El presente artículo propone analizar modelos de asistencia social implantados y operacionalizados en universidades públicas paulistas y proponer, a través del modelado organizacional basado en la metodología EKD (Enterprise Knowledge Development), modelos de objetivos, reglas, procesos y actores que apuntan a mapear requisitos técnicos y componentes operacionales estratégicos que garanticen la aplicación eficaz de los recursos financieros, viabilizando políticas sostenibles referenciadas por los principios constitucionales de legalidad, eficiencia e interés público.

${ }^{1}$ Universidade Estadual Paulista Faculdade de Ciências e Letras da UNESP Araraquara 


\section{INTRODUÇÃo}

As complexidades das questões relacionadas às políticas públicas de assistência estudantil no Brasil são equivalentes às oportunidades de inovação nos modelos, tradicionalmente assistencialistas (LEITE, 2008). As políticas de assistência estudantil no país tiveram origem na República Velha do governo Washington Luís, garantindo moradia na Casa do Estudante Brasileiro em Paris (1928), para uma elite de brasileiros que estudavam em Paris. Por iniciativa do governo de Getúlio Vargas em instituir programas de alimentação e moradia nas universidades recém-criadas, instalou-se a Casa do Estudante do Brasil em 1930, em um casarão de 3 andares com restaurante popular acoplado (DUTRA; SANTOS, 2015), onde originou-se a criação da União Nacional dos Estudantes (UNE) em 1937.

Prevista na Constituição Federal Brasileira desde 1946 e 1967, a assistência estudantil, atualmente referenciada pela constituinte de 1988, em seu artigo 206 dispõe: que o ensino deverá ser ministrado com base em alguns princípios sendo o primeiro: "I - igualdade de condições para o acesso e permanência na escola" (BRASIL, 1988), igualmente ao artigo $3^{\circ}$ da Lei de Diretrizes e Bases da Educação - LDB.

Atualmente o governo federal, através do Programa Nacional de Assistência Estudantil (PNAES), transformada no Decreto Presidencial no 7.234/2010 (BRASIL, 2010), busca padronizar e enumerar essas ações (moradia estudantil, alimentação, transporte, saúde, inclusão digital, cultura, esporte, creche e apoio pedagógico), porém a autonomia das universidades ao utilizar seus recursos no atendimentos dos requisitos, conforme necessidades e especificidades locais, não consideram algumas delas como assistência estudantil (ANDRADE; TEIXEIRA, 2017; FEITOSA, 2001).

A multiplicidade de abordagens, resultante das especificidades regionais, dificultam pesquisas qualitativas sobre os efeitos da assistência estudantil no rendimento acadêmico, predominando análises quantitativas sobre a evasão e dificuldades socioeconômicas, em detrimento da coleta e análise de aspectos psicossociais, cognitivos e afetivos. Essas capacidades citadas também sustentam habilidades de aprendizagem e síntese que influenciam a formação do indivíduo, bem como as competências técnicas e instrumentais que moldam sua qualificação profissional (NEVES; GARRIDO; SIMÕES, 2015).

Considerando-se aspectos político-administrativos da assistência estudantil, centrada na tomada de decisão por gestores (reitores, pró-reitores e assessores e sua predominância na condução das ações efetivas) torna-se aconselhável a inserção de alunos, docentes e técnicos-administrativos, atuando não somente na operacionalização dos processos burocráticos de conferência de documentos, entrevistas e avaliações socioeconômicas, mas na efetiva elaboração e planejamento dos programas sociais. (DUTRA; SANTOS, 2017). Ao formalizar o envolvimento da comunidade nas definições das políticas e ações de assistência, oferecendo um canal interativo de atendimento, legitima-se este processo de concessão de benefício custeado por verba pública, garantindo a transparência dos gastos, preconizada na legislação brasileira (BRASIL, 2011).

\section{AMParo SOCIOECONÔMICO OU PERMANÊNCIA ESTUdANTIL ?}

Estudos demonstram que o viés assistencialista destas políticas públicas tem sentido pejorativo de auxílio ou favor, estigmatizando os beneficiários que acessam um direito constitucional que minimiza os efeitos das desigualdades regionais e sociais do Brasil (LEITE, 2008; 2012; ZAGO, 2006). Mesmo no estado de São Paulo, o mais desenvolvido economicamente do país, as desigualdades ensejam as mesmas políticas de amparo estudantil preconizadas pelo PNAES e avalizadas pelas instâncias de serviço social das universidades públicas paulistas (FEITOSA, 2001). No âmbito estadual, aqui definido como o principal recorte temático e metodológico do objeto deste estudo, são observadas ações efetivas de amparo, também chamadas de políticas de permanência estudantil, nas três universidades estaduais paulistas: $\mathrm{USP}^{2}$, $\mathrm{UNESP}^{3}$ e UNICAMP ${ }^{4}$. Em todas elas foram criadas instâncias centrais responsáveis pela aplicação dos recursos de assistência estudantil, mas as unidades (campus ou faculdades) têm autonomia para gerir os processos de atribuição de auxílios e bolsas.

${ }^{2}$ Universidade de São Paulo

${ }^{3}$ Universidade Estadual Paulista

${ }^{4}$ Universidade Estadual de Campinas 


\section{UNESP (Universidade Est adual Paulista)}

No caso da UNESP, a Coordenadoria de Permanência Estudantil ${ }^{5}$ (COPE) relata em seu site ${ }^{6}$, que dos alunos matriculados em 2017, 52,3\% eram oriundos de escolas públicas e 18\% eram pretos, pardos e índios, informando que todos os alunos que solicitam apoio e atendem os requisitos de seleção são atendidos por pelo menos uma das modalidades de auxílio, desde 2014. O investimento previsto em bolsas e apoio de permanência estudantil pela UNESP para o ano de 2018 é de R \$41.388.000,00 (quarenta e um milhões, trezentos e oitenta e oito mil reais), segundo dados da COPE, sendo que no período de 2014 a 2017 a Unesp atendeu a 13.336 (treze mil, trezentos e trinta e seis estudantes).

Quadro 01 - Auxílios oferecidos pela UNESP com base em critérios socioeconômicos.

\begin{tabular}{|l|l|}
\hline Auxílio Socioeconômico & Apoio de permanência do aluno no mesmo no local da universidade \\
\hline Moradia Estudantil & Vagas em unidade residencial com regimentos/regulamentos próprios \\
\hline Auxílio Aluguel & Auxílio financeiro onde não houver vagas ou Moradia Estudantil \\
\hline Auxílio Especial & Estudante com deficiência, mobilidade reduzida ou doenças graves \\
\hline Auxílio Provisório & Apoio socioeconômico entre a matrícula e o fim do Processo Seletivo \\
\hline Subsídio Alimentação & Auxílio de natureza alimentar aos bolsistas de outras modalidades \\
\hline Auxílio Estágio & Auxílio ao aluno que realiza estágio em município diferente ao do campus \\
\hline Auxílio Transporte & Auxílio ao aluno que reside em Moradia Estudantil de difícil acesso/distante \\
\hline
\end{tabular}

Fonte: $\mathrm{COPE}^{7}$.

\section{UNICAMP (UNIVERSIDADE DE CAMPINAS)}

Na UNICAMP o SAS (Serviço da Assistência Social), vinculado ao Serviço de Apoio ao Estudante, desenvolve metodologia de análise global, na qual a avaliação está amparada em aspectos econômicos e socioculturais dos alunos, repensando os processos seletivos e ampliando as disposições e abrangências dos serviços oferecidos. O Sistema Integrado de Gestão - SIG ${ }^{8}$ é um instrumento de integração e gerenciamento das diferentes áreas da unidade voltado ao atendimento dos diversos usuários, sejam funcionários, alunos ou professores, propõe um sistema participativo de gerenciamento modular das demandas atuais e futuras.

Quadro 02 - Auxílios oferecidos pela UNICAMP com base em critérios variados.

\begin{tabular}{|l|c|}
\hline Bolsa Auxílio Social - BAS & Socioeconômico \\
\hline Bolsas Aluno-Artista - AA & Socioeconômico \\
\hline Bolsa Auxílio Moradia - MO & Socioeconômico \\
\hline Bolsa Alimentação e Transporte - BAT & Socioeconômico \\
\hline Bolsa Auxílio Estudo Formação - BAEF & Ambos \\
\hline Bolsa Pesquisa Empresa & Acadêmico \\
\hline Moradia Estudantil & Socioeconômico \\
\hline Bolsa Auxílio Instalação - BAI & Socioeconômico \\
\hline Bolsa Auxílio Social de Iniciação Científica - BASIC & Ambos \\
\hline Programa de Formação Interdisciplinar Superior - PROFIS & Acadêmico \\
\hline
\end{tabular}

Fonte: $\mathrm{SAE}^{9}$

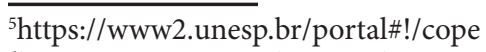

${ }^{6}$ https://www2.unesp.br/portal\#!/noticia/32952/avanco-na-permanencia-estudantil

${ }^{7}$ https://www2.unesp.br/portal\#!/cope

${ }^{8} \mathrm{https://www.sae.unicamp.br/sig/}$

${ }^{9} \mathrm{https}: / /$ www.portal.sae.unicamp.br/index.php/pt/sae
} 
No caso da UNICAMP, o SAE, além das demandas de serviço social e gerenciamento de bolsas-auxílio, oferece orientação pedagógica, jurídica, ações culturais e apoio a estágios e intercâmbios. Entre 2014 e 2017, a universidade atendeu 11.641 solicitações de amparo estudantil, tendo investido em $2018, \mathrm{R} \$ 85,895,00$ milhões, que corresponde a 23,96\% do Orçamento de Custeio da Universidade para 2018 ( $\mathrm{R} \$ 358,272$ milhões) ${ }^{10}$.

\section{USP (Universidade de São Paulo)}

A USP é a maior e mais conceituada universidade de São Paulo e do Brasil, com custeio de R \$ 73.380.000,00 (setenta e três milhões, trezentos e oitenta mil reais) distribuídas entre auxílios concedidos com base em critérios socioeconômicos do Programa de Apoio à Permanência e Formação Estudantil (PAPFE) (R\$ 35.980.000,00) e pelo Programa Unificado de Bolsas (PUB) com R \$37.400.000,00 (trinta e sete milhões e quatrocentos mil reais), através da Superintendência de Assistência Social (SAS) ${ }^{11}$.

Quadro 03 - Auxílios oferecidos pela USP com base em critérios socioeconômicos.

\begin{tabular}{|l|l|}
\hline Moradia & Ajuda de custo para moradia fora dos campi \\
\hline Alimentação & Gratuidadeemalmoçoejantarnosrestaurantesuniversitários \\
\hline Livro & Auxílio mensal para adquirir livros na Edusp \\
\hline Transporte & Ajudadecustocomtransporte(somentenoscampidointerior) \\
\hline CRUSP & Vaga em quarto no Conjunto Residencial da USP \\
\hline Apoio Manutenção (EACH) & Auxílio mensal apenas para alunos da USP Leste \\
\hline
\end{tabular}

Fonte: PAPFE ${ }^{12}$

Na USP, o Programa Unificado de Bolsas de Estudos para Apoio e Formação de Estudantes de Graduação (PUB-USP) embora integrado à Política de Apoio à Permanência e Formação Estudantil, visa engajar os discentes em atividades de investigação científica ou projetos associados às atividades-fim da universidade, contribuindo na formação acadêmica e profissionais dos bolsistas, que devem apresentar desempenho acadêmico e dedicação compatíveis com o plano de trabalho proposto por um docente ${ }^{13}$.

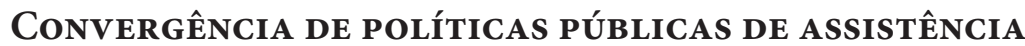

Fica evidente constatar a emergência espontânea de um padrão que converge modalidades similares de atendimento aos perfis equivalentes dos alunos das universidades paulistas. Em todas as três, predomina uma carência de requisitos básicos de permanência, como moradia, transporte e alimentação, sendo alguns, apenas variações ou complementações destes auxílios. Porém, embora sejam de natureza essencial, os editais de algumas modalidades cobram uma contrapartida, seja em forma de prestação de serviços à comunidade ou a obtenção de notas acima da média formal. Essa exigência estimula o estudante a buscar qualificação profissional e obter bolsas com melhores subsídios ou estágio melhor remunerado.

Nas modalidades de bolsas da UNICAMP, os apoios acadêmicos em projetos de pesquisa e extensão também são mediados pela mesma equipe de gestão de assistência estudantil, porém com critérios e finalidades diferentes. Também são oferecidas modalidades de formação interdisciplinar e iniciação científica que existem na USP e UNESP com nomenclaturas diferentes ou de forma complementar aos programas federais e estaduais de fomento (PIBIC, FAPESP, REITORIA, PIBID, PIBIT)

Ao tabular os dados dos quadros 01, 02 e 03, inferem-se semelhanças nas modalidades de assistência estudantil das universidades estaduais paulistas, predominando moradia, transporte e alimentação em suas variações de finalidade.

\footnotetext{
${ }^{10} \mathrm{http}: / /$ www.unicamp.br/unicamp/informacao/proposta-de-distribuicao-orcamentaria

${ }^{11}$ http://www.usp.br/vrea/files/orc2018/POUSP2018-Q6.pdf

${ }^{12} \mathrm{http}: / /$ sites.usp.br/sas/papfe/

${ }^{13} \mathrm{http}: / /$ www.prg.usp.br/wp-content/uploads/EDITAL_PUB_USP_2018_2019.pdf
} 
Quadro 04 - Tabulação de dados sobre os tipos de auxílios das Universidades Estaduais Paulistas.

\begin{tabular}{|l|l|l|l|}
\hline \multicolumn{1}{|c|}{ Modalidade } & \multicolumn{1}{|c|}{ USP } & \multicolumn{1}{c|}{ UNESP } & \multicolumn{1}{c|}{ UNICAMP } \\
\hline Habitação & Auxílio Moradia e CRUSP & $\begin{array}{l}\text { Auxílio Aluguel, Provisório e } \\
\text { Moradia Estudantil }\end{array}$ & $\begin{array}{l}\text { Auxílio Moradia, Instalação, e } \\
\text { Moradia Estudantil }\end{array}$ \\
\hline Alimentação & Alimentação & Subsídio alimentação & Alimentação e Transporte \\
\hline Transporte & Transporte e emergencial & $\begin{array}{l}\text { Auxílio transporte, auxílio está- } \\
\text { gio e auxílio especial }\end{array}$ & Alimentação e Transporte \\
\hline Permanência & Apoio manutenção & Auxílio socioeconômico & Auxílio Social \\
\hline Outras modalidades & Auxílio livro & & $\begin{array}{l}\text { Bolsa aluno-artista e estudo- } \\
\text {-formação }\end{array}$ \\
\hline
\end{tabular}

Fonte: Pesquisa de Campo.

Objetivando a redução do objeto deste estudo, focado na assistência estudantil, foram analisados dados dos auxílios socioeconômicos na USP, UNESP e UNICAMP, realizando uma separação conceitual das bolsas de apoio acadêmico ou similares, que não estão diretamente relacionadas à permanência estudantil ou não se enquadram como amparo socioeconômico. Os modelos organizacionais contemplarão apenas os quatro primeiros itens das modalidades do quadro 05 , que equivalem aos principais auxílios oferecidos nas três universidades.

Quadro 05 - Dotação orçamentária dos tipos de auxílios nas Universidades Estaduais Paulistas.

\begin{tabular}{|l|c|c|}
\hline Universidade & Custeio Total & Forma de apuração \\
\hline USP & $73.380 .000,00^{14}$ & Dotação orçamentária 2018 \\
\hline UNESP & $41.388 .000,00^{15}$ & Estimativa pela média mensal de Janeiro a outubro de 2018 \\
\hline UNICAMP & $85.895 .000,00^{16}$ & Proposta de distribuição orçamentária 2018 \\
\hline Totais Gerais & $200.663 .000,00$ & Projeções e execuções em relatórios de transparência \\
\hline
\end{tabular}

Fonte: Pesquisa de Campo.

As modalidades de bolsas de suporte acadêmico, extensão universitária, de iniciação científica e outras variações, oferecidas com nomenclaturas diferentes em cada universidade, também podem contemplar alunos que recebem auxílios socioeconômicos, porém a cumulatividade com bolsas de agências de fomento (CA$\mathrm{PES}^{17}, \mathrm{FAPESP}^{18}, \mathrm{CNPQ}^{19} \mathrm{e}$ outras) não é permitida em alguns casos, pelas próprias agências ou pelas próprias universidades.

O investimento em amparo socioeconômico e/ou permanência estudantil das três universidades estaduais paulistas perfazem aproximadamente $2,12 \%$ do montante recebido pela cota parte de $9,57 \%$ do ICMS do estado de Sâo Paulo ${ }^{20}$ projetado para 2018, no montante de R $\$ 9,452,880,008,00$ (nove bilhões, quatrocentos e cinquenta e dois milhões, oitocentos e oitenta mil e oito reais), conforme planilha abaixo:

\footnotetext{
${ }^{14} \mathrm{http} / / /$ www.usp.br/vrea/files/orc2018/POUSP2018-Q6.pdf

${ }^{15}$ https://www2.unesp.br/Home/aplo/ddp-outubro-2018.pdf

${ }^{16} \mathrm{http}: / /$ www.unicamp.br/unicamp/informacao/proposta-de-distribuicao-orcamentaria

${ }^{17}$ Coordenação de Aperfeiçoamento de Pessoal de Nível Superior

${ }^{18}$ Fundação de Amparo à Pesquisa do Estado de São Paulo

${ }^{19}$ Conselho Nacional de Desenvolvimento Científico e Tecnológico

${ }^{20} \mathrm{http}$ ://www.orcamento.planejamento.sp.gov.br/visualizar-pdf/custeio-autarquias
} 
Planilha 01 - Projeção de repasse da cota parte do ICMS às universidades paulistas - 2018.

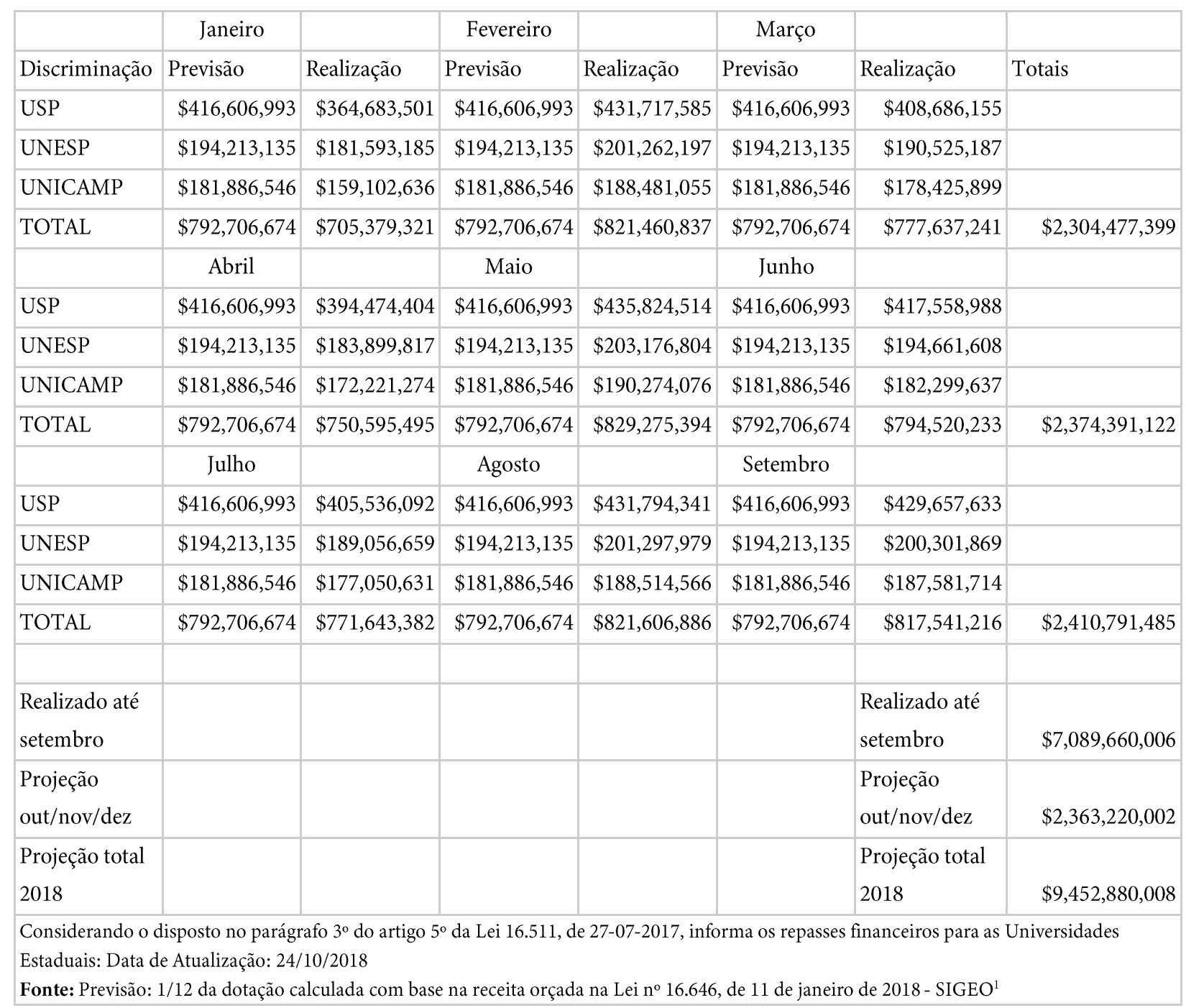

Fonte: Autoria própria.

Dados coletados em: https://portal.fazenda.sp.gov.br/acessoinformacao/Paginas/Repasses-para-Universidades.aspx

\section{MODELAgEM ORgANIZACIONAL}

Após analisar dados dos modelos de assistência social e de permanência estudantil implantados e operacionalizados nas três universidades públicas paulistas, este estudo objetiva propor modelos de objetivos, regras, processos e atores que visam mapear requisitos técnicos e componentes operacionais estratégicos através da modelagem organizacional baseada na metodologia EKD (Enterprise Knowledge Development) que garantam a aplicação eficaz dos recursos financeiros, viabilizando políticas sustentáveis referenciadas pelos princípios constitucionais de legalidade, eficiência e interesse público.

Metodologia de MOdelagem ORgANizACional BASEAdA EM EKD (ENTERPRise KNOWLEDge DeVELOPMENT)

A modelagem organizacional teve origem nos princípios da Modelagem Empresarial ou Corporativa (EM) $)^{21}$ introduzidas na Suécia nos anos 80 e aperfeiçoada pelo Swedish Institute for System Development (SISU) ${ }^{22}$ até 2001, consistindo basicamente em métodos de estruturação do conhecimento de empresas ou corporações (BUBENKO et al., 2001).

Segundo Bubenko et al. (2001), ao simular diferentes visões do modelo corporativo, as equipes podem otimizar o planejamento estratégico através da reengenharia contínua dos objetivos e regras do negócio e melhorar o planejamento dos recursos humanos, materiais e informacionais.

${ }^{21}$ https://www.techopedia.com/definition/28051/enterprise-modeling

${ }^{22} \mathrm{https} / / /$ link.springer.com/chapter/10.1007/978-3-642-23315-9_40 
A abordagem do EKD considera que os objetivos de uma empresa ou negócio definem suas regras, que por sua vez definem os processos, descrevendo quais requisitos devem ser atendidos e como os recursos serão disponibilizados pelos atores, mapeando quais relacionamentos entre as áreas envolvidas decorrem dessa modelagem, conforme demonstrado na figura 01 e no quadro 06 :

Quadro 06 - Tipos e finalidades de modelos no EKD.

\begin{tabular}{|l|l|}
\hline \multicolumn{1}{|c|}{ Tipo de Modelo } & \multicolumn{1}{c|}{ Finalidade } \\
\hline Objetivos & Definem as prioridades, políticas e caminhos da corporação, sua importância e dificuldades \\
\hline Regras & Definem os limites dos objetivos e quais regras são estruturantes ou delimitantes do negócio \\
\hline Processos & Definem os fenômenos, informações e ações previstas nos modelos de objetivos e regas \\
\hline Conceitos & Esclarece quais premissas e diretrizes orientam as atividades e como serão fiscalizadas \\
\hline Atores e Recursos & Relatam quais entidades e instâncias serão envolvidos nos processos e como se relacionam \\
\hline Recursos e componentes técnicos & Definem os requerimentos para definição do sistema de informações que alimentará o modelo \\
\hline
\end{tabular}

Fonte: Próprio autor, baseado em BUBENKO et al., 2001.

Figura 01 - Submodelos que compõem a modelagem EKD e seus relacionamentos.

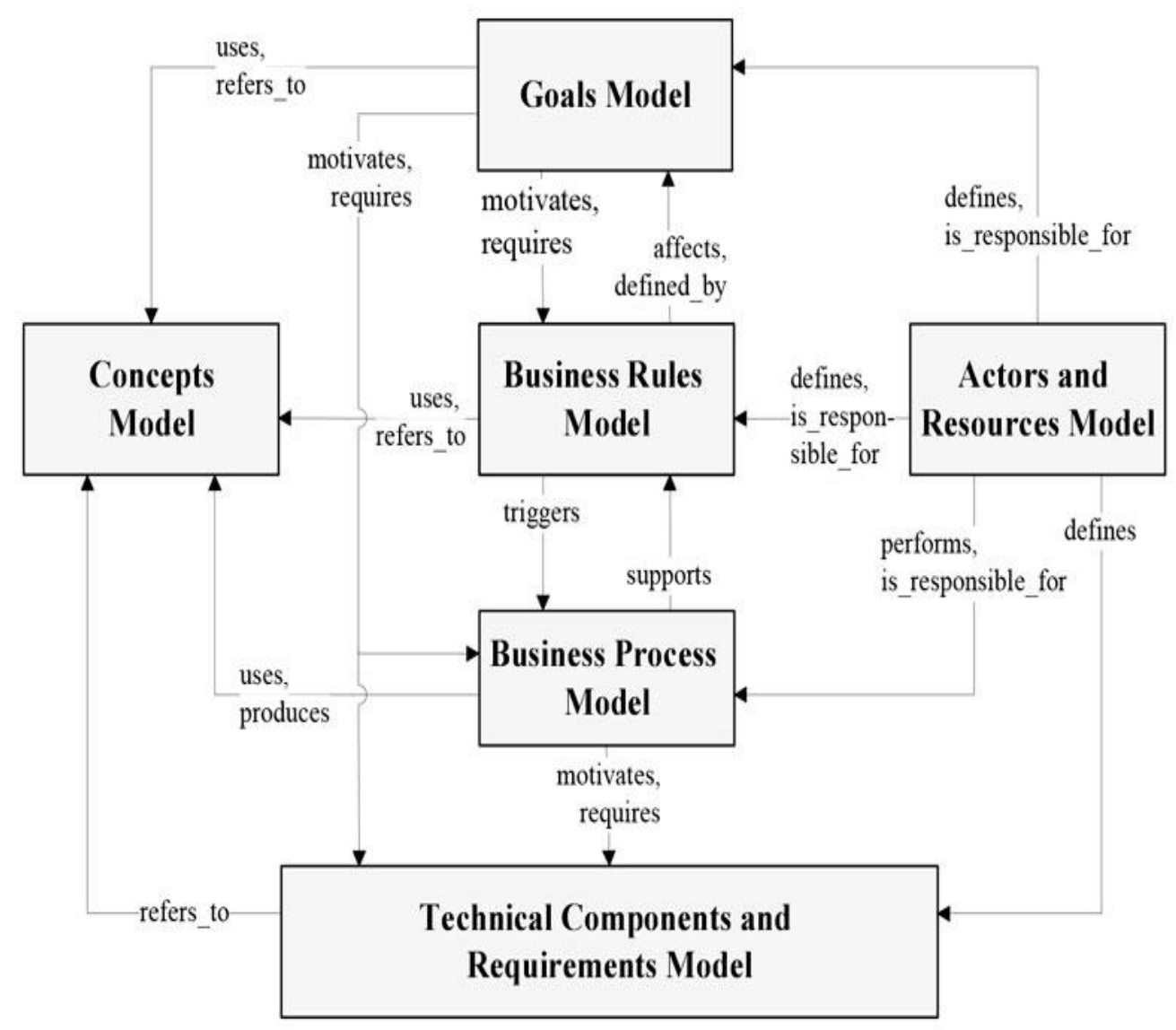

Fonte: BUBENKO et al., 2001. 
Com a crescente complexidade das infraestruturas de sistemas de informações nas corporações, emerge a necessidade de uma notação padronizada que descreva formalmente uma estrutura organizacional, permitindo:

1. comparações entre a situação presente e uma situação futura,

2. comparações entre e dentro das empresas,

3. comparações e soluções geradas por computador e

4. utilização da informação resultante como base para informatizar um sistema de informação (SI).

\section{OS MODELOS DE OBJETIVOS FUTUROS}

Um dos objetivos centrais do estudo realizado é modelar um serviço de assistência social estudantil que garanta aplicação eficaz dos recursos financeiros públicos de forma sustentável, atendendo os princípios constitucionais de legalidade, eficiência e interesse público. Para atender essas premissas, os modelos de objetivos futuros foram desenvolvidos por um grupo de alunos, como um dos trabalhos de conclusão da disciplina Modelagem de Empresas: Conceitos e Métodos, no qual o autor está incluído, da Pós-Graduação em Engenharia de Produção na Escola de Engenharia da USP de São Carlos em 2018, ministrada pelos professores Fábio Muller Guerrini e Edson Walmir Cazarini.

Os debates em torno da proposta inicial de modelagem indicaram que os conceitos centrais não deveriam ser, necessariamente, baseados nos atuais modelos de assistência estudantil, buscando a inovação e até mesmo a disruptura em relação aos mesmos. Também houve consenso, sob orientação dos professores, de buscar simplificar a linguagem utilizada no modelo para atender um dos requisitos do EKD, que consiste em produzir modelos que possam ser compreendidos e atualizados por qualquer membro da organização (GUERRINI et al, 2014).

\section{Modelo de Objetivos}

Figura 02 - Modelo de objetivos futuros.

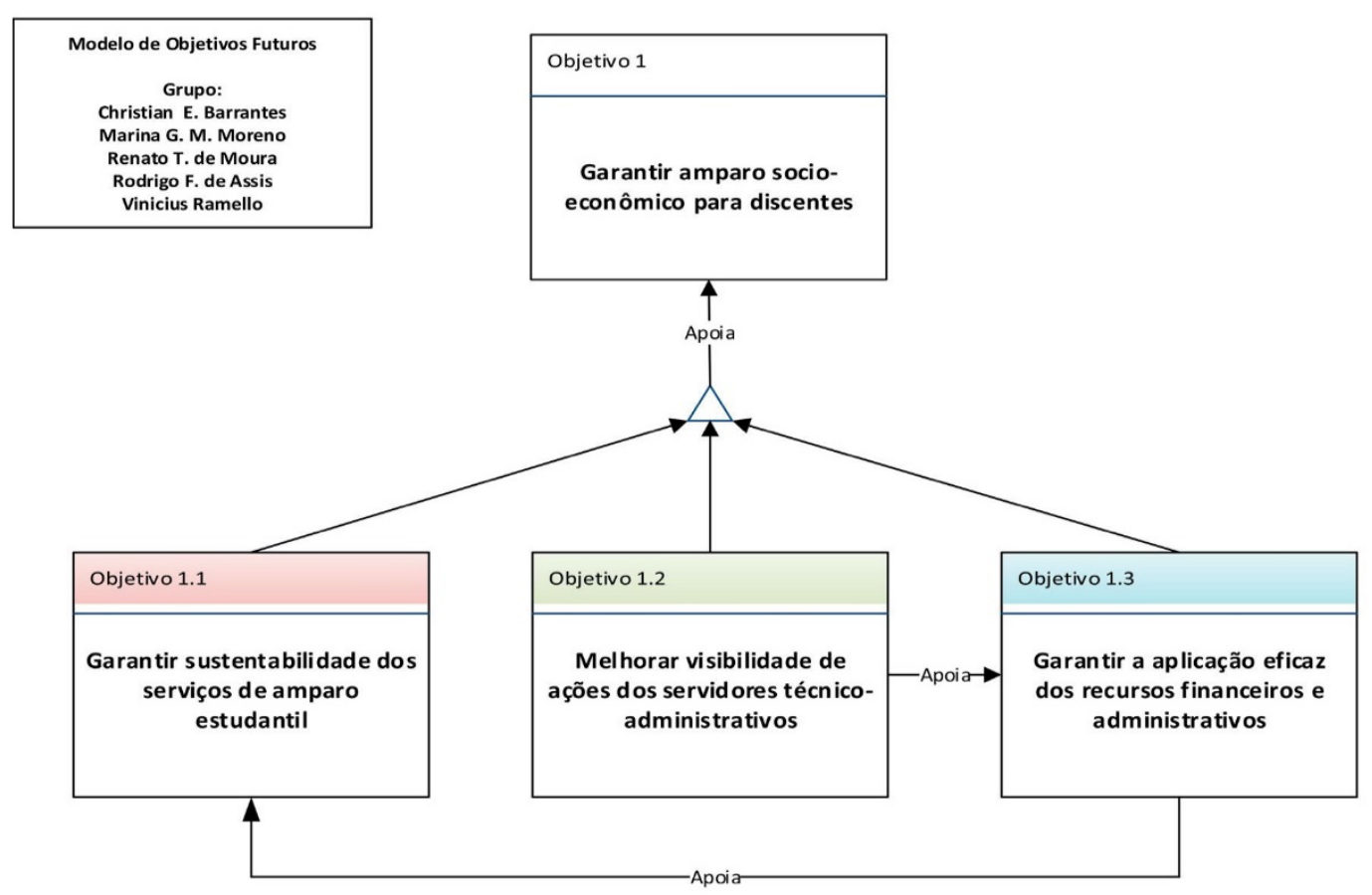

Fonte: O autor e seu grupo de estudos na EESC-USP. 
O objetivo central 1 é simples e direto, bem como os subníveis que dele derivam e são a síntese das regras que orientam as ações que garantam os mesmos. A generalização dos termos e simplificação no modelo de objetivos e regras visam facilitar o desenvolvimento dos modelos de processos, que irão detalhar como serão alcançados os mesmos de acordo com as regras estabelecidas, conforme as figuras 03, 04 e 05.

\section{MODELOS DE OBJETIVOS E REGRAS}

Figura 03 - Modelo de objetivos e regras.

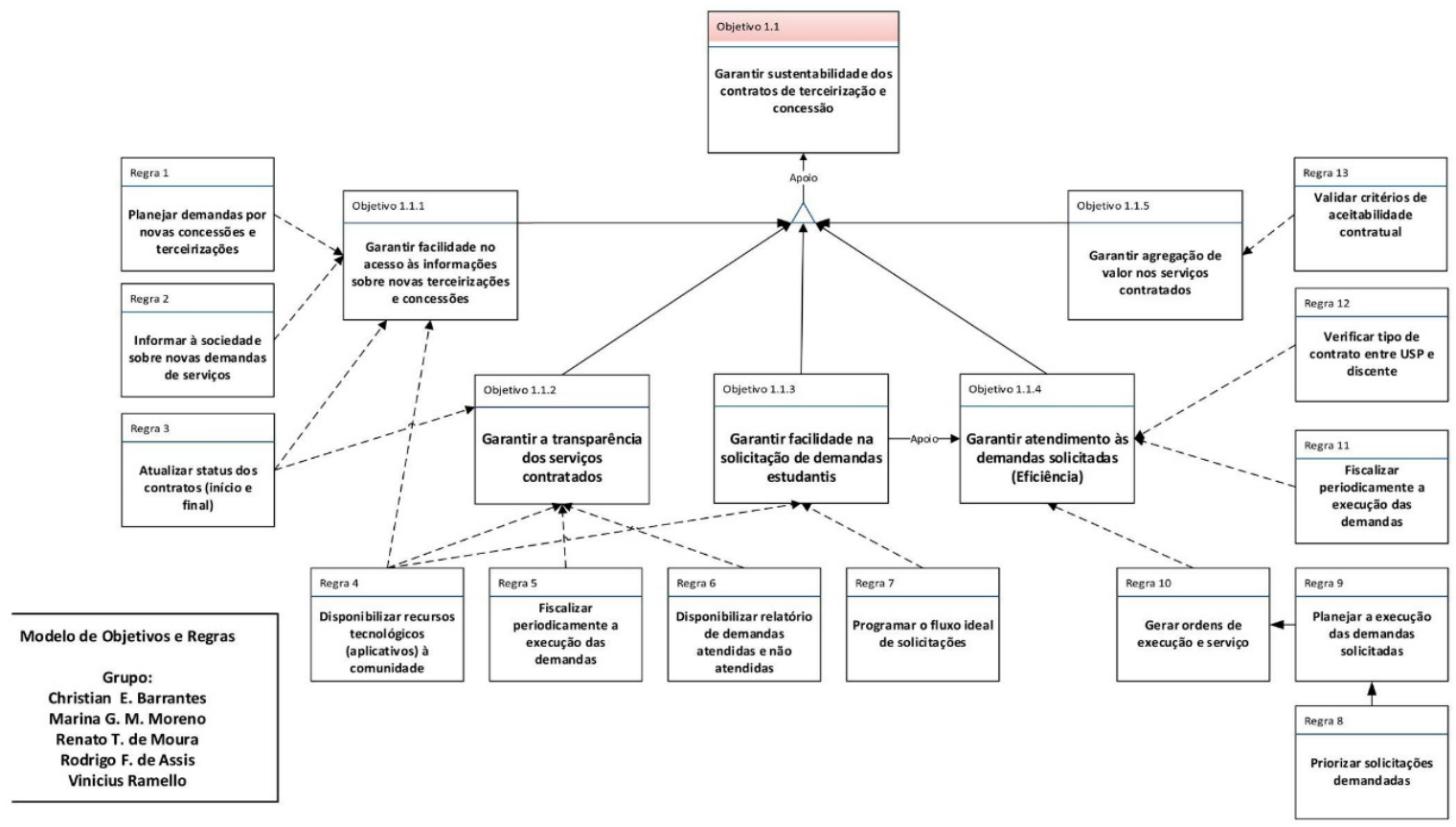

Fonte: $\mathrm{O}$ autor e seu grupo de estudos na EESC-USP.

Figura 04 - Modelo de objetivos e regras.

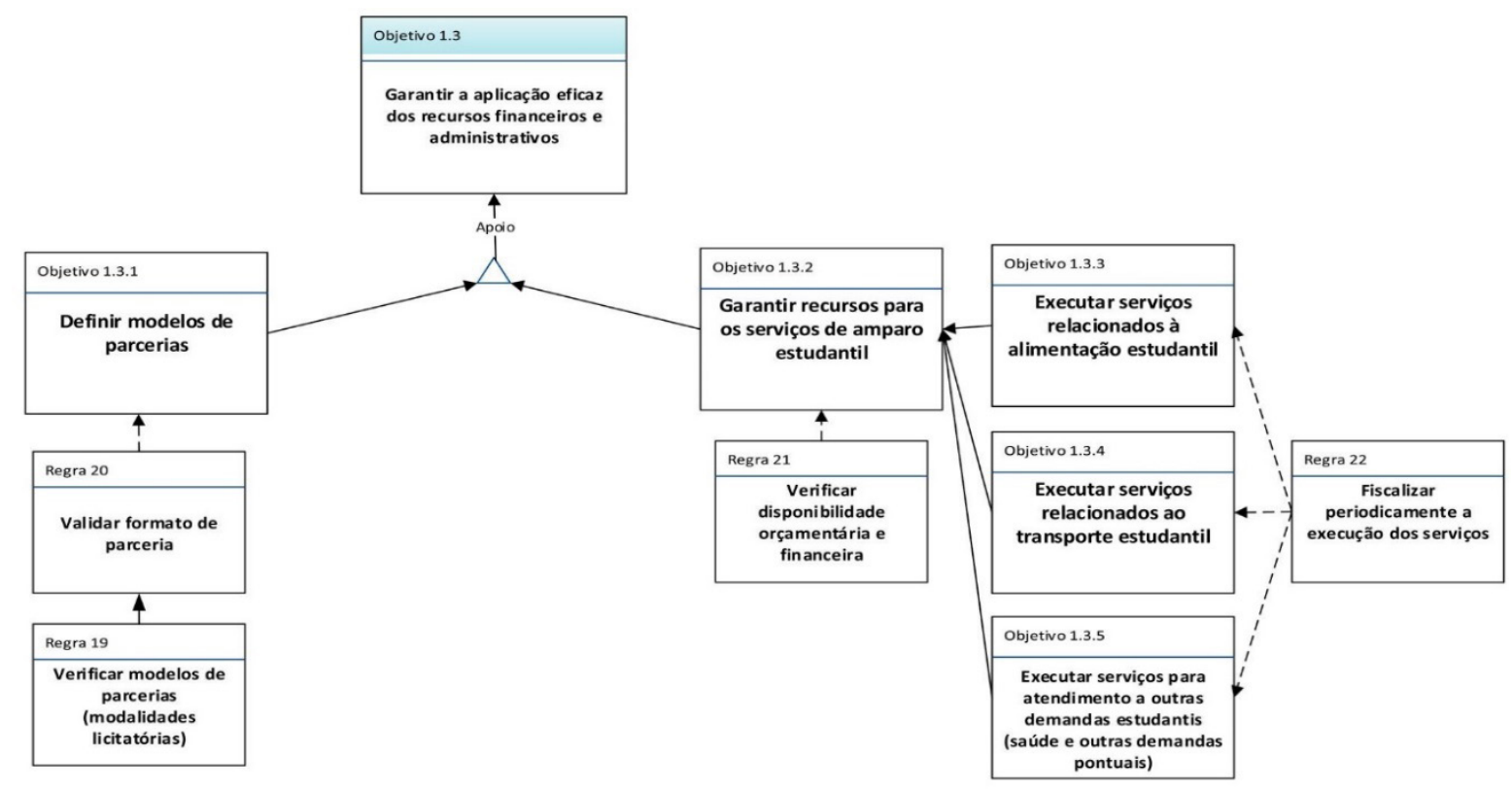

Fonte: $\mathrm{O}$ autor e seu grupo de estudos na EESC-USP. 
Figura 05 - Modelo de objetivos e regras.

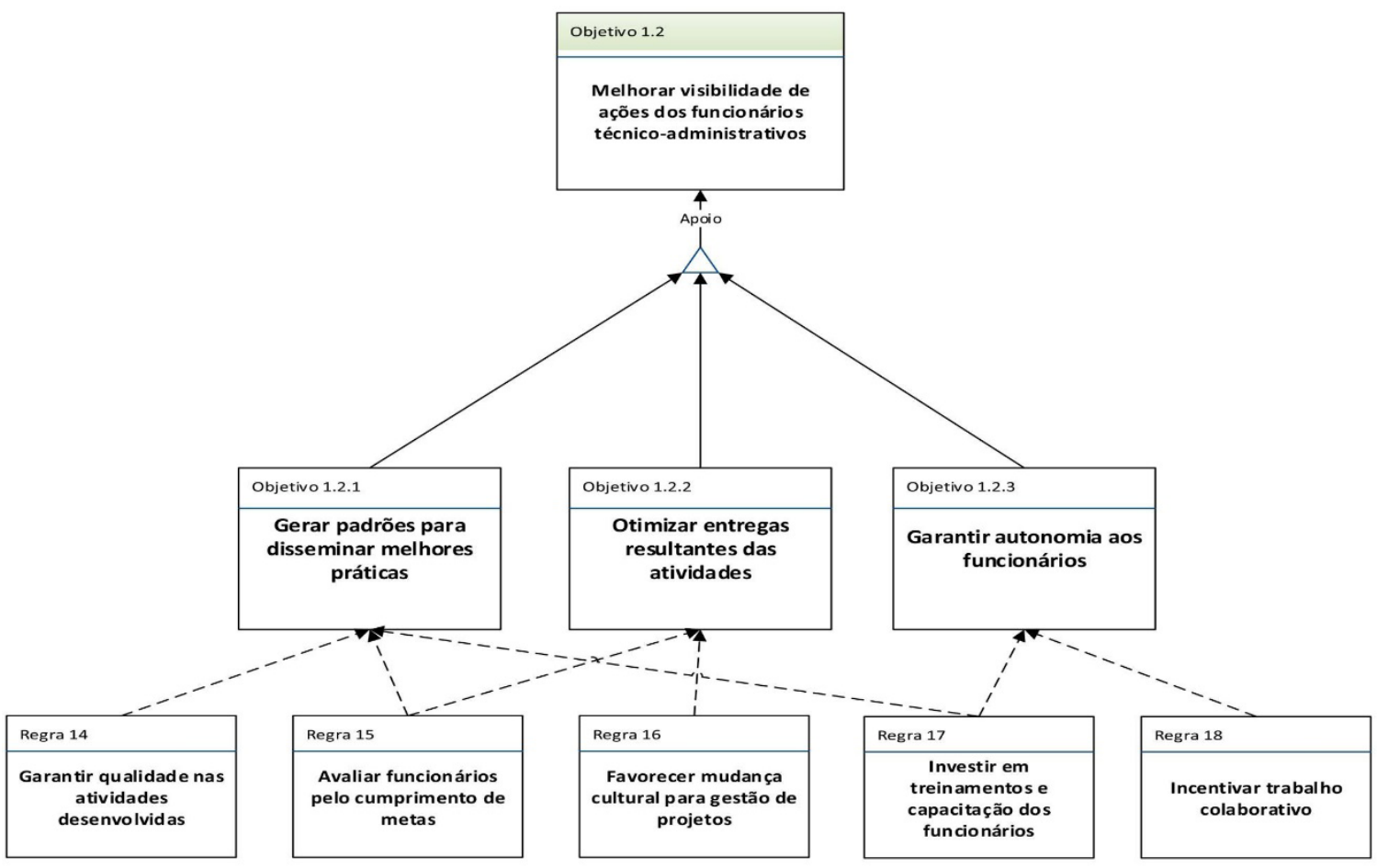

Fonte: $\mathrm{O}$ autor e seu grupo de estudos na EESC-USP.

\section{MODELOS DE PROCESSOS}

Modelo de Processos descrevem como e quais processos irão gerar fluxos de informação e circulação/modificação de materiais na organização. O modelo pode mapear as atividades e processos do negócio já consolidados ou previstos para implantação (GUERRINI et al., 2014).

Figura 06 - Modelo de processos 1.3.1 e 1.3.2.

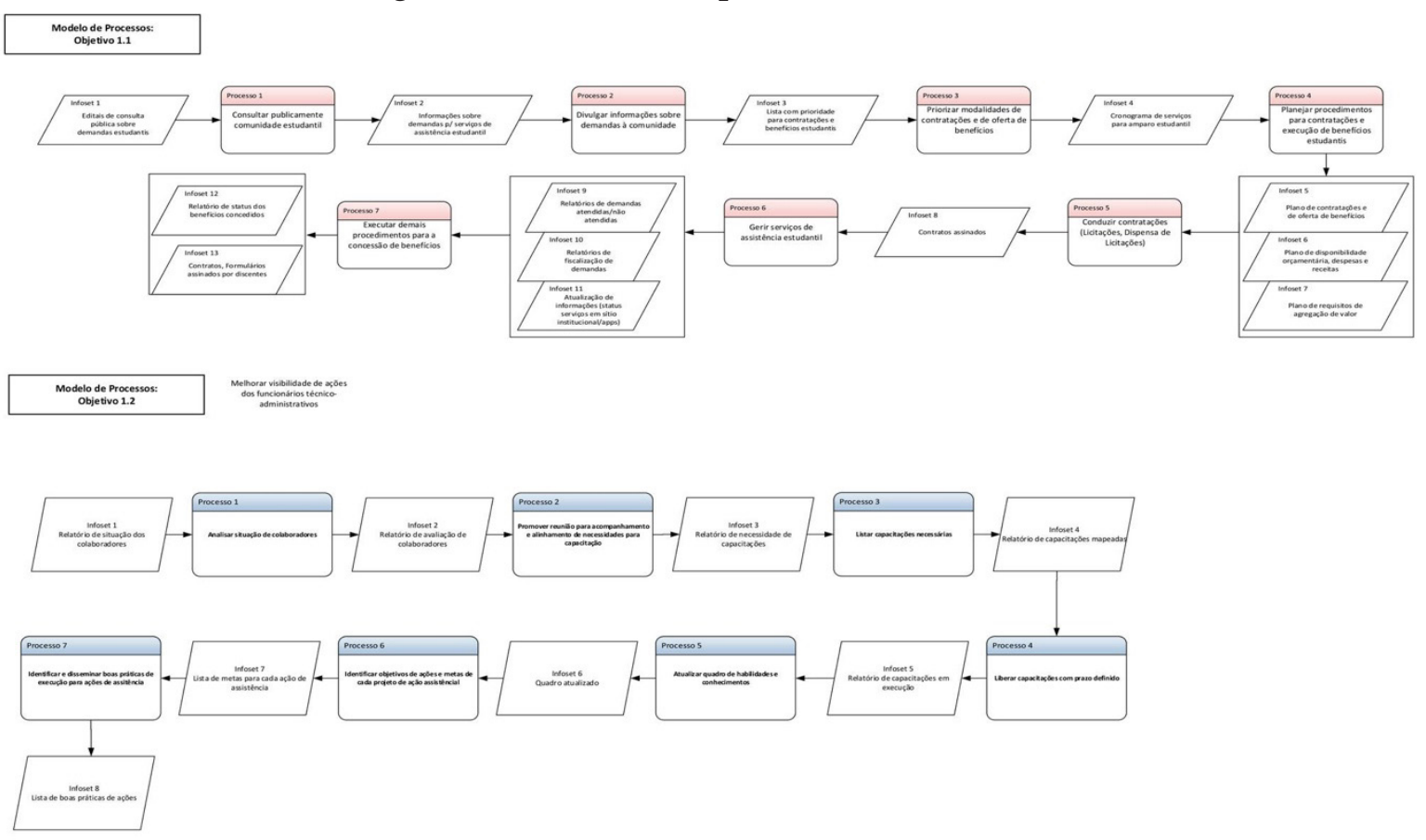

Fonte: $\mathrm{O}$ autor e seu grupo de estudos na EESC-USP. 
Figura 07 - Modelo de processos 1.3.1, 1.3.2, 1.3.3, 1.3.4 e 1.3.5.

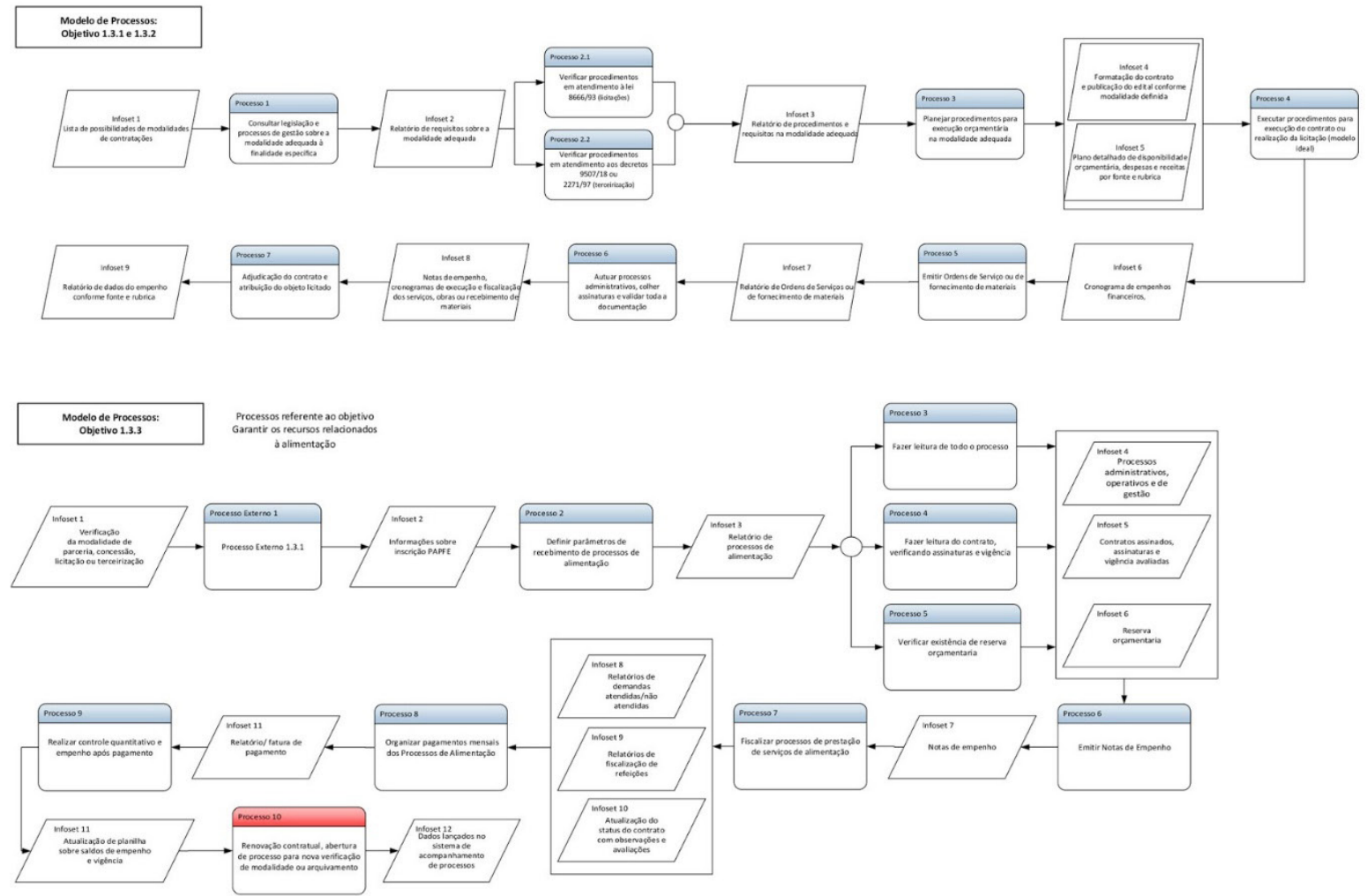

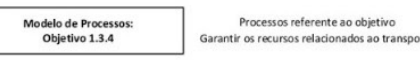
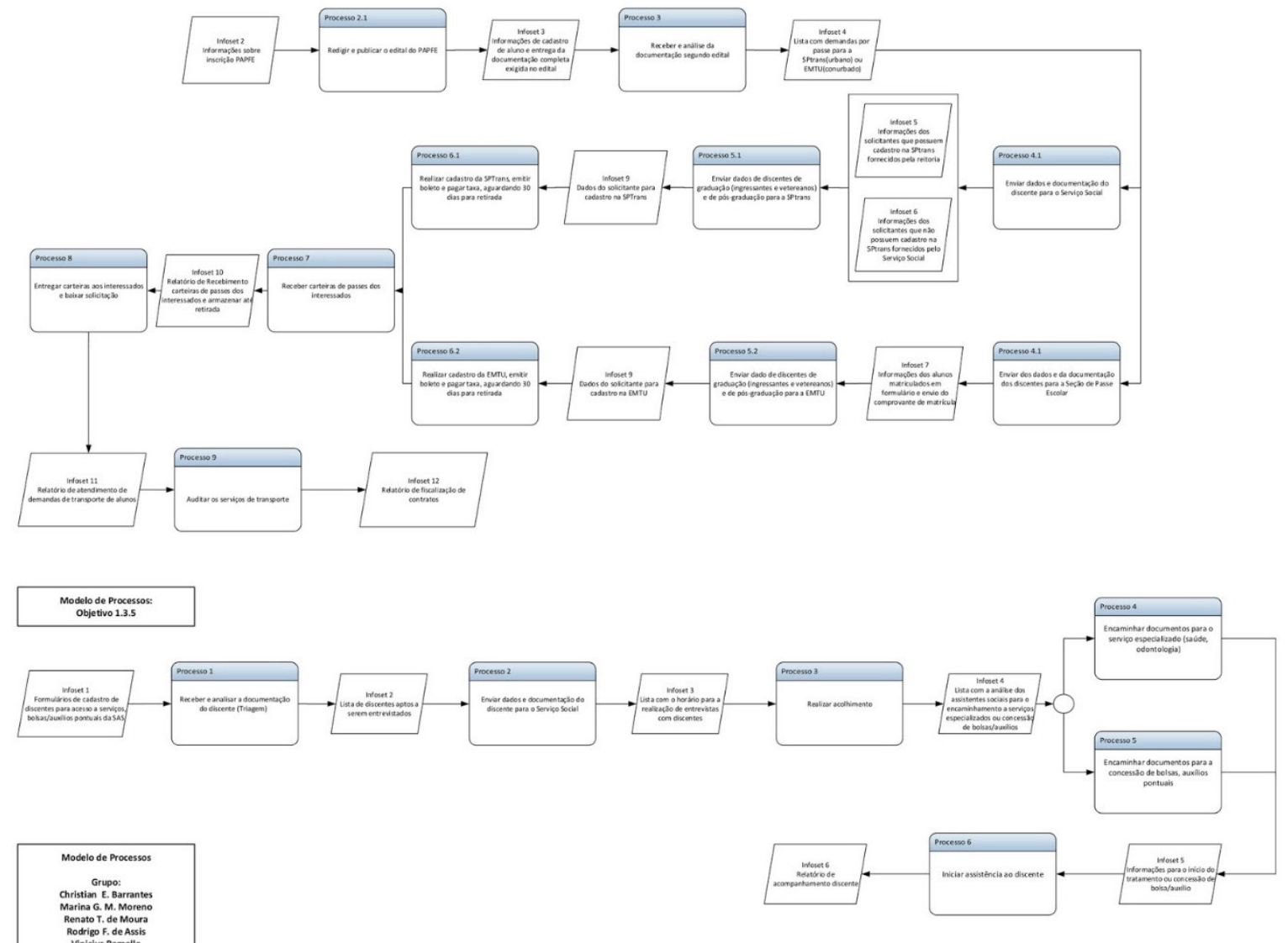

Fonte: $\mathrm{O}$ autor e seu grupo de estudos na EESC-USP. 


\section{MODELO DE ATORES E RECURSOS}

Segundo Guerrini et all, (2014), o modelo descreve diferentes atores e recursos e seus relacionamentos aos componentes dos modelos anteriores, definindo quais atores respondem por quais processos e recursos, de acordo com quais regras e objetivos.

Figura 08 - Modelo de atores e recursos.

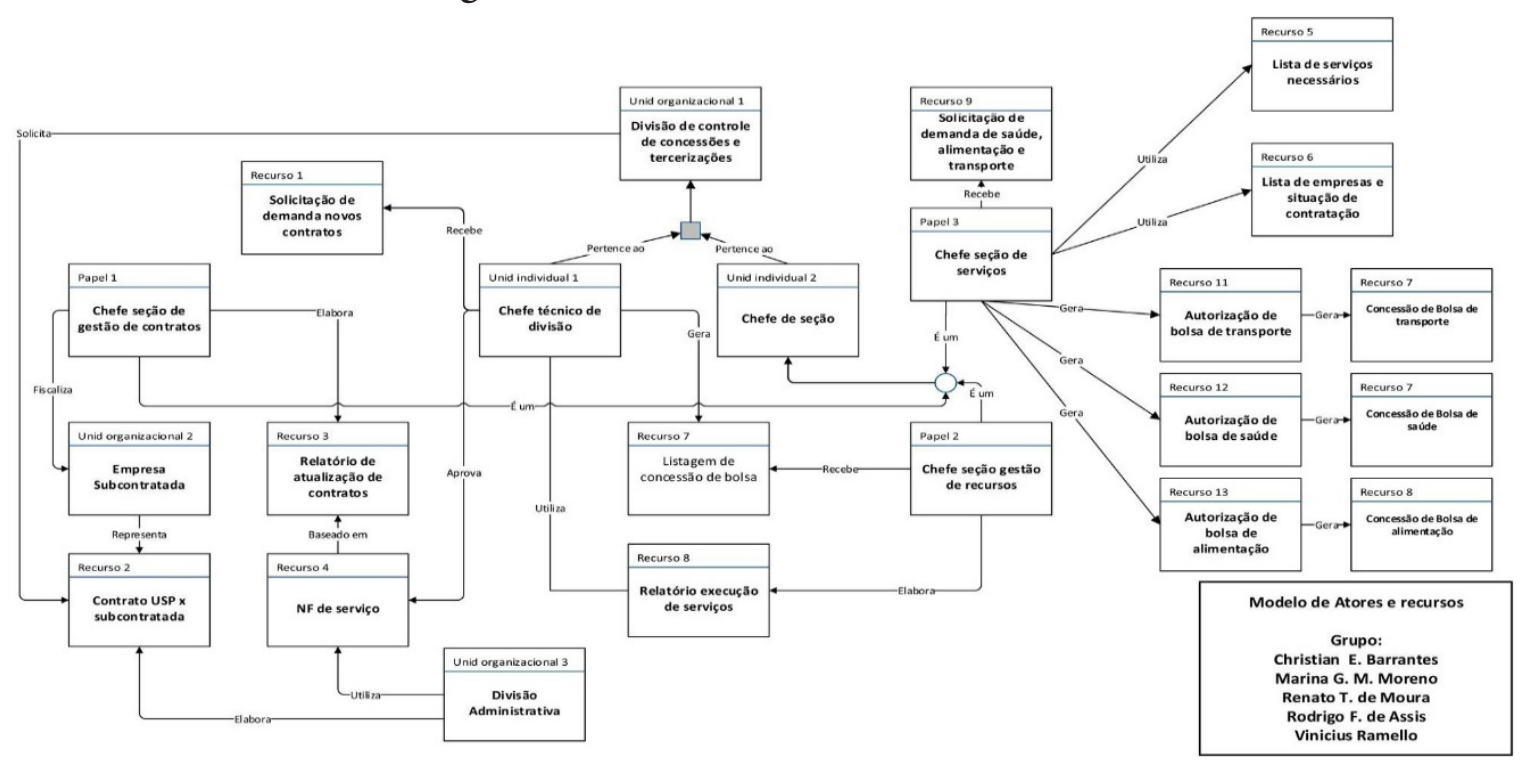

Fonte: O autor e seu grupo de estudos na EESC-USP.

\section{MODELO DE COMPONENTES E REQUISITOS}

Determina quais estruturas e propriedades dos sistemas de informações devem sustentar e apoiar os processos para atingir os objetivos do modelo.

Figura 09 - Modelo de Componentes e requisitos.

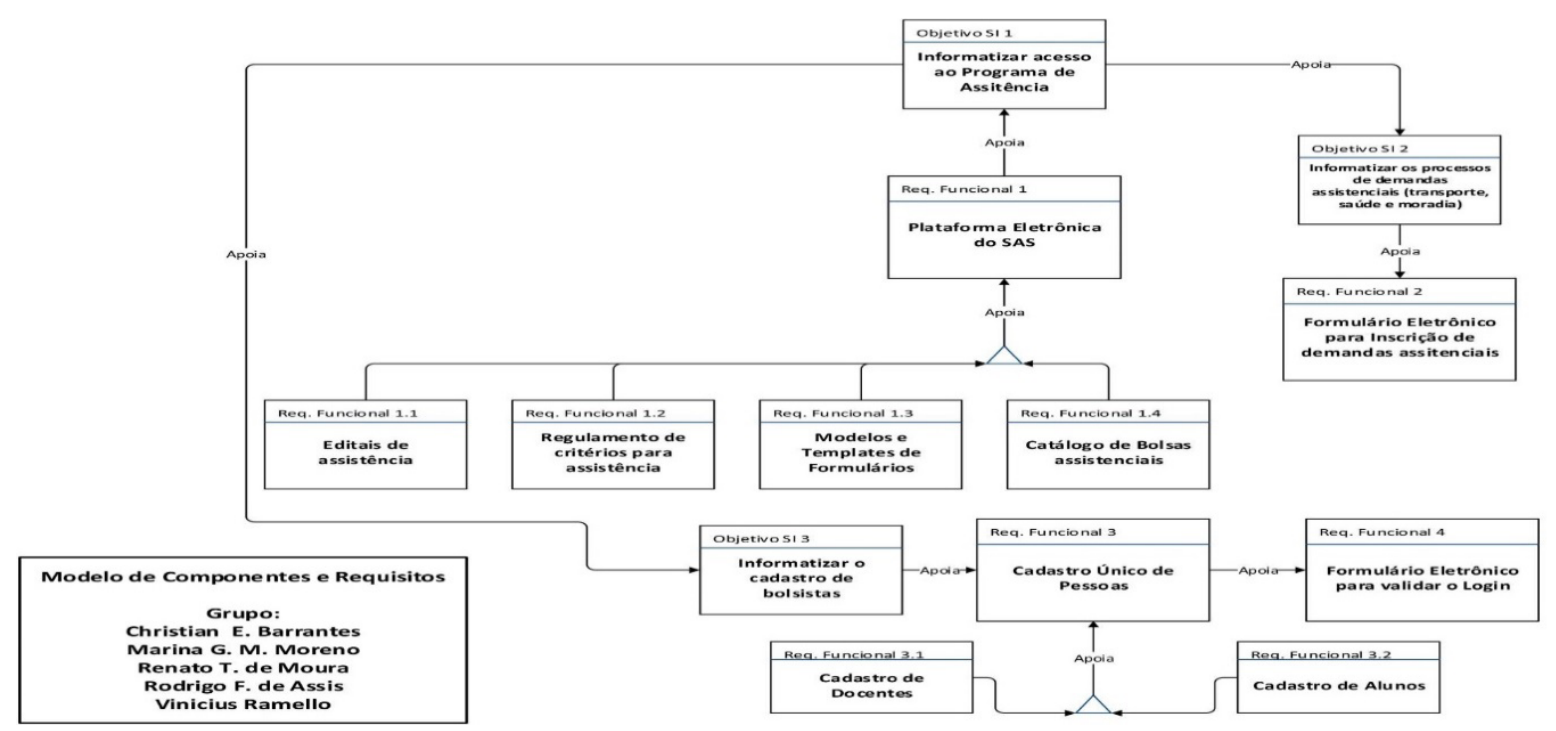

Fonte: O autor e seu grupo de estudos na EESC-USP.

\section{CONSIDERAÇões FINAIS}

As organizações ou empresas que buscam obter vantagens competitivas otimizando seus modelos, também revisam constantemente a essência do negócio ou serviço, que embora não dependa diretamente da tecnologia, são consideradas como sistemas de informação apoiadas pela gestão do conhecimento, ao serem abordadas como um sistema complexo e orgânico (PAULA; SANTOS; ROVER, 2011; MATURANA; VARELA, 1995). 
Segundo Rossetti e Tcholakian Morales (2007), ainda persiste no Brasil, em outros países e regiões, a visão equivocada de que a Tecnologia de Informação (IT) e a Gestão do Conhecimento (KM) sejam a mesma coisa. Também é notório que recursos tecnológicos de informação não podem gerenciar o conhecimento, conceito já superado há décadas nas corporações orientais. (FAYYAD; PIATETSKY-SHAPIRO; SMYTH, 1996).

Ao propor modelar um serviço essencial de assistência socioeconômico, prestado diretamente ao aluno de universidade pública por um aplicativo de smartphone, além de gerenciar o relacionamento entre eles, permitirá que o mesmo participe de alguns processos decisórios e indique, diretamente à entidade gestora, suas necessidades e demandas de forma transparente.

Os Sistemas de Informações resultante da modelagem devem sustentar e apoiar os processos para atingir os objetivos do modelo proposto, revisando estruturalmente a entidade corporativa ao retroalimentar sua cadeia de decisões, mantendo sua organicidade através da análise dinâmica dos resultados e revisão dos processos e objetivos. Tudo referenciado pela circularidade, preconizada por Maturana e Varela (1995), da gestão do conhecimento, como no conceito de Open Science, sintetizado por Fecher e Friesike (2013), aqui em tradução livre:

Open Science é um termo genérico que abrange uma variedade de suposições sobre o futuro da criação e difusão do conhecimento, propondo cinco escolas de pensamento: a escola de infraestrutura (que é preocupada com a arquitetura tecnológica), a escola pública (que é preocupado com a acessibilidade da criação de conhecimento), a escola da mensuração(que se preocupa com a medição do impacto alternativo), a escola democrática (que se preocupa com o acesso ao conhecimento) e escola pragmática (que se preocupa com pesquisa colaborativa) (FECHER; FRIESIKE, 2013).

\section{REFERÊNCIAS}

ANDRADE, Ana Maria Jung de; TEIXEIRA, Marco Antônio Pereira. Áreas da política de assistência estudantil: relação com desempenho acadêmico, permanência e desenvolvimento psicossocial de universitários. Avaliação (Campinas), Sorocaba, v. 22, n. 2, p. 512-528, ago. 2017 . Disponível em: <http://www.scielo.br/ scielo.php?script=sci_arttext\&pid=S1414-40772017000200512\&lng=pt\&nrm=iso $>$. Acesso em 03 nov. 2018.

BRASIL. Presidência da República. Decreto no 7.234, de 19 de julho de 2010. Dispõe sobre o Programa Nacional de Assistência Estudantil - PNAES. Diário Oficial da União, Brasília/DF, 20 jul. 2010. Seção 1, p. 5. Disponível em: <http://www.planalto.gov.br/ccivil_03/_Ato2007-2010/2010/Decreto/D7234.htm>. Acesso em 05 nov. 2018

BRASIL. Lei de Regulação do Acesso à Informação no 12.527, de 18 de Novembro de 2011. Disponível em: <http://www.planalto.gov.br/ccivil_03/_ato2011-2014/2011/lei/112527.htm>.

BRASIL. Lei de Diretrizes e Bases da Educação Brasileira no 9394, de 01 de dezembro de 1996. Disponível em: <http://www2.camara.leg.br/legin/fed/lei/1996/lei-9394-20-dezembro-1996-362578-publicacaooriginal-1-pl.html>. Acesso em 06 nov. 2018.

BUBENKO J. A. et al. (2001). D3 Appendix B: EKD User Guide. Stockholm, Sweden: Royal Institute of Technology (KTH) and Stockholm University, 2001. Disponível em < ftp://ftp.dsv.su.se/users/js/ekd_user_guide 2001.pdf $>$. Acesso em 10 out. 2018.

DUTRA,NatáliaGomesdosReis;SANTOS, MariadeFátimadeSouza. Assistênciaestudantilsobmúltiplosolhares: a disputa de concepções. Ensaio: aval. pol. públ. Educ., Rio de Janeiro, v. 25, n. 94, p. 148-181, Mar. 2017. Disponível em <http://www.scielo.br/scielo.php?script=sci_arttext\&pid=S0104=40362017000100148-\&lng=en\&nrmiso $>$. Acesso em 04 nov. 2018.

CAMPOS, V. R.; CAZARINI, E. W. Gestão de Compras na Administração Pública Utilizando Modelagem Organizacional. In: XVI Simpósio de Engenharia de Produção, Bauru, 2009. Anais - SIMPEP. Bauru: UNESP, 
2009. v. XVI.

CAMPOS, V. R.; CAZARINI, E. W.; CASTILLO, L. A. M. Modelagem de Apoio à Decisão Multicritério Utilizando a Metodologia EKD. Anais do Encontro Nacional de Engenharia de Produção - ENEGEP, 2010. Disponível em: <http://www.abepro.org.br/biblioteca/enegep2010_TN_STO_118_770_15289.pdf >. Acesso em 09 nov. 2018.

FAYYAD, Usama; PIATETSKY-SHAPIRO, Gregory; SMYTH, Padhraic. From Data Mining to Knowledge Discovery in Databases. AI Magazine, 1996, n. 17, p. 37-54. Disponível em <http://www.csd.uwo.ca/faculty/ling/ cs435/fayyad.pdf>. Acesso em 14 nov. 2018

FECHER, B.; FRIESIKE, S. Open Science: One Term, Five Schools of Thought. RatSWD Working Paper Series 218. 2013. Disponível em <http://www.ratswd.de/dl/RatSWD_WP_218.pdf >.

FEITOSA, Marcos Gilson Gomes. Integração de estudantes ingressantes à vida universitária: fatores que facilitam e que dificultam sua integração. 2001. Tese (Doutorado em Educação). Faculdade de Educação, Universidade Federal de São Carlos, São Carlos/SP, 2001.

GUERRINI, Fábio Müller et al. Modelagem da Organização: Uma Visão Integrada. Porto Alegre, RS: Bookman, 2014.

LEITE, Janete Luzia. Política de assistência estudantil: entre o direito e o favor. Universidade e Sociedade, v. 27, n. 41, p. 165-73, 2008.

LEITE, Janete Luzia. Política de Assistência Estudanti: direito da carência ou carência de direitos? Revista SER Social, v. 14, n. 31, p. 453-472, 2012. Disponível em <http://www.scielo.br/pdf/rk/v14n1/v14n1a03.pdf>. Acesso em 09 nov. 2018.

MATURANA, H. R.; VARELA, F. A árvore do conhecimento: as bases biológicas do entendimento humano. Campinas, SP: Psy II, 1995.

NEVES, José; GARRIDO, Margarida Vaz; SIMÕES, Eduardo. Manual de competências pessoais, interpessoais e instrumentais: teoria e prática. $3^{\text {a }}$ ed. Lisboa: Sílabo, 2015.

PAULA, Giovani; SANTOS, Paloma; ROVER, Aires. O Uso de Sistemas de Informação e Conhecimento nas Atividades de Inteligência do Estado: Um Olhar sob a Perspectiva da Segurança Pública. 2011. Disponível em <https://www.researchgate.net/publication/277020728_O_Uso_de_Sistemas_de_Informacao_e_Conhecimento_nas_Atividades_de_Inteligencia_do_Estado_Um_Olhar_sob_a_Perspectiva_da_Seguranca_Publica $>$. Acesso em 03 nov. 2018.

ROSSETTI, Adroaldo Guimarães; TCHOLAKIAN MORALES, Aran Bey. O papel da tecnologia da informação na gestão do conhecimento. Ciência da Informação, [S.1.], v. 36, n. 1, dec. 2007. Disponível em: <http:// revista.ibict.br/ciinf/article/view/1191/1362>. Acesso em: 14 nov. 2018.

ZAGO, N. Do acesso à permanência no ensino superior: percursos de estudantes universitários de camadas populares. Revista Brasileira de Educação, Campinas/SP, v. 11, n. 32, 2006. 